4.2.5. Mối liên quan giữa đăc điểm trong sinh với kết quả chăm sóc. Kểt quả bảng 3.6 cho thấy nhóm sản phụ võ̃ ối đúng lúc có kết quả chăm sóc tốt cao gấp 2,57 lần nhóm vỡ ối non, võ sớm (95\%CI: 1,326 - 5,005; $p<0,05$ ). Như vậy nghiên cứu tìm được mối liên quan giữa tình trạng vỡ ối với kết quả chăm sóc.

Cùng với đặc điểm ối vỡ, nghiên cứu cũng tìm được mối liên quan có ý nghĩa thống kê giữa thời gian rặn đẻ với kết quả chăm sóc sản phụ ( $p$ $<0,05)$. Nhóm sản phụ có thời gian rặn đẻ ngắn và bình thường có kết quả chăm sóc tốt cao gấp nhiêu lần nhóm sản phụ có thời gian rặn đẻ kéo dài $(\mathrm{OR}=9,89 ; 95 \% \mathrm{CI}: 3,289-29,77 ; \mathrm{p}<0,001)$ và $(O R=5,278 ; 95 \% C I: 2,359-11,807 ; p<0,001)$. Sản phụ có thời gian rặn đẻ lâu, kéo dài sẽ mệt, mất sức và đau nhiều, sự hợp tác với nhân viên y tế thường không tốt nên kết quả chăm sóc kém hơn các sản phụ có thời gian rặn đẻ ngắn và bình thường.

4.2.6. Mối liên quan giữa học lớp tiền sản và kết quả chăm sóc sản phụ. Tìm hiểu mối liên quan giữa học lớp tiền sản với kết quả chăm sóc, kết quả nghiên cứu cho thấy nhóm sản phụ/chồng/cả hai vợ chồng tham gia lớp học tiên sản có kết quả chăm sóc tốt cao gấp 2,287 lần nhóm cả hai vợ chồng không tham gia học $(\mathrm{OR}=2,287 ; 95 \% \mathrm{CI}: 1,245-4,198 ; \mathrm{p}<0,05-$ bảng 3.7).

Những sản phụ đã tham gia học lớp tiền sản, quá trình tư vấn, hướng dẫn các sản phụ của nhân viên y tế rất thuận lợi, sản phụ và người nhà hợp tác khá tốt. Sản phu thường hiểu rõ diễn biến cuộc chuyển dạ, có sự sẵn sàng về tâm lý, biết được những thay đổi của cơ thể qua mỗi giai đoạn, chuẩn bị kĩ về thể chất và tinh thần để chào đón em bé. Sản phụ có thể vượt can dễ dàng vì đã hợp tác toàn diện với nhẩn viên y tế nên biết thực hành đúng cách thở, cách rặn đẻ, cách giảm đau, cách chăm sóc sơ sinh....

\section{KẾT LUẬN}

Kết quả nghiên cứu cho thấy số sản phụ được chăm sóc tốt chiếm tỉ lệ cao $80,9 \%$.

Nghiên cứu đã xác định được một số yếu tố: Điều kiện kinh tế, số lần đẻ, tình trạng phá thai, tâm lý sản phụ, tham gia học lớp tiền sản, thời gian chuyển dạ, dấu hiệu sinh tồn, mức độ đau, ối võ̃ non-võ sớm, thời gian rặn đẻ có mối liên quan có ý nghĩa thống kê với kết quả chăm sóc sản phụ của nhân viên y tế.

\section{TÀI LIẸU THAM KHẢO}

1. Bộ môn Phụ Sản, Học viện Quân y (2019), Băi giảng sản phụ khoà, Nhà xuất bản Quân đội nhân dân, Hà Nôi.

2. UNICEF (2009), Sức khỏe bà me và trẻ sơ sinh

3. Bộ Y tế (2018), Báo cáo hộ sinh Việt nam lần thứ nhất.

4. Bô Y tế (2011), Thông tư số 07 , Hướng dẫn công tác điểu dưỡng chăm sóc người bênh trong bệnh viện.

5. Lê Thu Đào (2012), Nghiền cứu tình hình chăm sóc bà me và trẻ sơ sinh sau mổ lấy thai tại Bênh viện đa khoa Trung ương Cần Thơ, Trường đại học Y Dước Cần Thơ.

6. Trân Thị Thu Hà (2014), Chăm sóc me và bé sơ sinh, Sổ tay 2 , Trung tâm nghiên cứu, đào tạo và phát triển công đồng.

7. Đào Nguyển Hùng (2017), Nghiên cứu vai trò người trơ sinh trong chuyến da và sau sinh tai Bệnh viện Quân y 103, Đê tài khoa học cấp Học viện Quấn y.

\title{
KẾT QUẢ ỨNG DỤNG NEURONAVIGATION PHẪU THUẬT U BÁN CẦU ĐẠI NÃO
}

TÓM TẮT

Mục tiêu: Nhận xét kết quả ứng dụng hệ thống Neuronavigation phẫu thuật u bán cầu đại não. Phương pháp: Mô tả cắt ngang, kết quả phẫu thuật 72 bệnh nhân u bán câu đại não có sử dụng hệ thống

\footnotetext{
*Trường Đại học Y Dược Thái Bình

**Bênh viện Việt Đức

Chiu trách nhiệm chính: Vũ Minh Hải

Email: vuminhhai777@gmail.com

Ngày nhận bài: 5.4.2021

Ngày phản biện khoa học: 24.5.2021

Ngày duyệt bài: 4.6.2021
}

\section{Dương Như Năm*, Vũ Minh Hải*, Đồng Văn Hệ***}

Neuronavigation trong phẫu thuật tại bệnh viện Việt Đức từ 10/2015 đến tháng 3/2016. Kết quả: 72 bẹnh nhân u bán cầu đại não gồm 27 nam (37,5\%), 45 nữ $(62,5 \%)$; Tuổi trung bình là $48,6 \pm 13,4$. Giải phẫu bệnh: 38 u màng não; 28 u thần kinh đệm; 5 u di cắn; Mức đô cắt bỏ u: $76,4 \%$ lấy toàn bô u, 18,1\% lấy u gần toàn bộ bảo vệ các cấu trúc quan trọng; Thời gian phẫu thuâte trung bình là $163,47 \pm 84,64$ phút; Thời gian điêu trị sau mổ trung bình là 7,06 $\pm 2,19$ ngày; 93\% bệnh nhân không phải truyền máu; 12,5\% biến chứng sau mổ; Kết quả sau mổ 3 tháng: Tốt $(55,6 \%)$, di chứng nhẹ $(31,9 \%)$ và $87,5 \%$ bệnh nhân có cải thiện chất lượng cuộc sống sau mổ (Karnofsky nhóm I, II). Kết luận: Ứng dụng Neuronavigation trong phẫu thuật u não bán cầu đại não giúp phẫu 
thuật viên tự tin cắt bỏ tối đa u não, bảo tồn vùng chức năng cho kết quả cải thiên chất lượng sống bệnh nhân cao.

Tư khóa: Neuronavigation trong phẫu thuật u não, u bán cầu đại não.

\section{SUMMARY \\ OUTCOMES OF CEREBRAL HEMISPHERE TUMOR SURGERY USING NEURONAVIGATION}

Objectives: to assess the outcomes of cerebral hemisphere tumor surgery using Neuronavigation. Methods: A descriptive cross-sectional study on surgical outcomes of 72 patients suffering cerebral hemisphere tumors operated with the assistance of Neuronavigation in surgery at Viet Duc hospital from October 2015 to March 2016. Results: 72 patients having cerebral hemisphere tumors included 27 males $(37.5 \%), 45$ females $(62.5 \%)$; The median age was $48.6 \pm$ 13.4. Pathology: 38 meningiomas; 28 gliomas; 5 metastatic brain tumors; The extent of tumor resection: $76.4 \%$ gross total resection, $18.1 \%$ almost total resection and protecting important structures. The average surgical time was $163.47 \pm 84.64$ minutes; The average time for postoperative treatment was $7.06 \pm 2.19$ days; $93 \%$ of patients did not require blood transfusion; $12.5 \%$ had postoperative complications; Outcome at 3 months post-operative period: Good $(55.6 \%)$, mild sequelae $(31.9 \%)$ and $87.5 \%$ of patients had improved quality of life after surgery (Karnofsky scale: I, II). Conclusion: The application of Neuronavigation in brain tumor surgery helps the surgeon confidently remove the brain tumor to the maximum extent, preserving the functional areas, giving patients the improvement in quality of life.

Keywords. Neuronavigation, cerebral hemisphere tumors.

\section{I. ĐẶT VẤN ĐỀ}

Ngày nay, cùng với sự tiến bộ của khoa học kỹ thuật, xu hướng chung của các phẫu thuật là xâm lấn tối thiểu. Với phẩu thuật thần kinh, điều này càng cần thiết vì dễ tổn thương nhu mô não lành ở xung quanh, đặc biệt ở những vùng quan trọng có chức năng sống còn với cơ thể. Hệ thống định vị thần kinh đã được ứng dụng nhiều trong các ca phẫu thuật u não ở Việt Nam. Để làm rõ hơn về những ưu điểm của hệ thống định vị chúng tôi đánh giá kết quả sau mổ 72 trường hợp u não vùng bán cầu được phẫu thuật có sự trợ giúp của hệ thống Neuronavigation.

\section{II. ĐỐI TƯỢNG VÀ PHƯƠNG PHÁP NGHIÊN CỨU}

2.1. Địa bàn nghiên cứu. Bênh viện Việt Đức

2.2. Đối tượng nghiên cứu. 72 bênh nhân u bán cầu đại não được phẫu thuật có sử dụng hệ thống Neuronavigation tại bệnh viện Việt Đức từ 10/2015 đến tháng 3/2016.

2.3. Phương pháp nghiên cứu. Mô tả cắt ngang kết quả phầu thuật 72 bệnh nhân u bán cầu đại não.

\section{KẾT QUẢ NGHIÊN CỨU}

Bảng 3.1. Phân bồ bệnh nhân theo nhóm tuổi

\begin{tabular}{|c|c|c|}
\hline Tuối & $\mathbf{n}$ & Tỷ lệ (\%) \\
\hline$\leq 20$ & 1 & 1,4 \\
\hline $21-40$ & 18 & 25,0 \\
\hline $41-60$ & 38 & 52,8 \\
\hline$>60$ & 15 & 20,8 \\
\hline Tống & $\mathbf{7 2}$ & $\mathbf{1 0 0}$ \\
\hline
\end{tabular}

Nhận xét: Lứa tuổi lao động (21-60 tuổi) chiếm $77,8 \%$

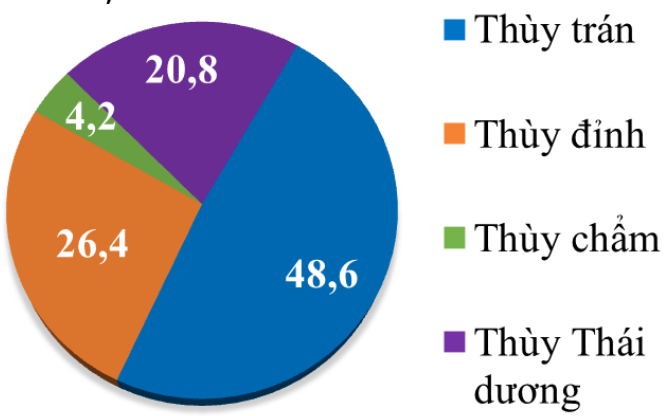

Biêu đồ 3.1. Vị trí u ở các thùy bán cầu đại não

Nhân xét: Có 35/72 u vi trí trán (48,6\%). U vùng chẩm có tỷ lệ thấp nhất (4,2\%). Vị trí u ở vùng đỉnh và thái dương là $26,4 \%$ và $20,8 \%$.

Bảng 3.2. Mức độ lấy u theo nhận định của phâuu thuật viên

\begin{tabular}{|c|c|c|}
\hline Mức độ lầy u & $\mathbf{n}$ & Tỷ lệ (\%) \\
\hline Toàn bộ & 55 & 76,4 \\
\hline Gần toàn bộ & 13 & 18,1 \\
\hline Bán phần & 3 & 4,2 \\
\hline Một phần & 1 & 1,4 \\
\hline Tống & $\mathbf{7 2}$ & $\mathbf{1 0 0}$ \\
\hline
\end{tabular}

Nhận xét: Lấy u toàn bộ chiếm $76,4 \%$; gần hết u 18,1\%

Thời gian phẫu thuật: Thời gian phẫu thuâtt trung bình là $163,47 \pm 84,64$ (phút), thấp nhất là 60 phút, cao nhất là 540 phút.

Bảng 3.3. Số lượng máu truyền trong và sau mồ

\begin{tabular}{|c|c|c|}
\hline Số lượng máu truyền & $\mathbf{n}$ & Tỷ lệ (\%) \\
\hline Không truyền & 67 & 93,0 \\
\hline$\leq 500 \mathrm{ml}$ & 2 & 2,8 \\
\hline $501-1000 \mathrm{ml}$ & 2 & 2,8 \\
\hline$>1000 \mathrm{ml}$ & 1 & 1,4 \\
\hline Tống & $\mathbf{7 2}$ & $\mathbf{1 0 0}$ \\
\hline
\end{tabular}

Nhận xét: 93\% bệnh nhân lấy u không cần truyên máu

Bảng 3.4. Phân loại u não theo mô bênh hoc

\begin{tabular}{|c|c|c|c|c|}
\hline Loại u & Độ & n & \multicolumn{2}{|c|}{ Tỷ lệ (\%) } \\
\hline \multirow{2}{*}{$\begin{array}{c}\text { U màng } \\
\text { não }\end{array}$} & I & 26 & 36,1 & \multirow{2}{*}{54,2} \\
\cline { 2 - 4 } & II & 11 & 15,3 & \\
\hline
\end{tabular}




\begin{tabular}{|c|c|c|c|c|}
\hline & III & 2 & 2,8 & \\
\hline \multirow{3}{*}{$\begin{array}{c}\text { Uin thân } \\
\text { kinh đệm }\end{array}$} & I & 4 & 5,6 & \\
\cline { 2 - 4 } & II & 9 & 12,5 & \multirow{3}{*}{38,9} \\
\cline { 2 - 4 } & III & 8 & 11,1 & \\
\cline { 2 - 4 } & IV & 7 & 9,7 & \\
\hline \multicolumn{2}{|r|}{ U di căn não } & 5 & \multicolumn{2}{|c|}{6,9} \\
\hline \multicolumn{2}{|r|}{ Tống } & $\mathbf{7 2}$ & \multicolumn{2}{|c|}{$\mathbf{1 0 0}$} \\
\hline
\end{tabular}

Nhânn xét: Trong 72 bênh nhân thì u màng não chiếm 54,2\%; U thần kinh đệm 38,9\%

Bảng 3.5. Đánh giá theo thang điểm Karnofsky sau khám lai $\geq 3$ tháng

\begin{tabular}{|c|c|c|}
\hline Phân loại theo Karnofsky & $\mathbf{n}$ & Tỷ lệ(\%) \\
\hline Nhóm I & 61 & 84,7 \\
\hline Nhóm II & 2 & 2,8 \\
\hline Nhóm III & 4 & 5,6 \\
\hline Nhóm IV & 5 & 6,9 \\
\hline Tổng & $\mathbf{7 2}$ & $\mathbf{1 0 0}$ \\
\hline
\end{tabular}

Nhận xét: Khám lại trung bình $\geq 3$ tháng theo Karnofsky thấy 84,7\% cải thiện chất lượng cuộc sống.

\section{BÀN LUÂN}

4.1. Tuổi, giới. 72 bệnh nhân, tuổi nhỏ nhất là 6 tuổi, lớn nhất là 74 tuổi, tuổi trung bình là $48,60 \pm 13,40$, kết quả này không khác biêt nhiêu với Kiều Đình Hùng (2010): $44 \pm 11$ tuổi [7] và Chu Tân Sĩ (2012): 50,22 \pm 11 tuổi, các tác giả đều cho rằng u não gặp nhiêuu nhất ở nhóm tuổi trên 40 tuổi [8].

Giới: Bệnh nhân nữ $(62,5 \%)$, nam chiếm $37,5 \%$, tỷ lệ nữ/nam là 1,67 phù hợp với tác giả Chu Tân Sĩ (2012) là 1,33 [8]. Tuy nhiên, do nghiên cứu chúng tôi chọn một số nhóm u để đánh giá ứng dụng hệ thống neuronavigation trong phẫu thuật, thời gian ngắn và cỡ mẫu không đủ lớn nên có thể không phản ánh đây đủ tân suất các nhóm tuổi, tân suất về giới của u vùng bán câu đại não.

4.2. Vị trí khối u. Nghiên cứu của chúng tôi, u não ở vùng trán chiếm tỷ lệ cao nhất 48,6\%, u ở vị trí vùng chẩm có tỷ lệ thấp nhất $4,2 \%$. Có 63 bệnh nhân u não nằm ở vị trí nông (phát hiện trên bề mặt não) chiếm $87,5 \%$ và 9 bệnh nhấn có u não nằm ở vị trí sâu (không thây trên bề mặt, ở dưới vỏ, các rãnh não, chất trắng, các nhân xám...) chiếm 12,5\%.

Chúng tôi đồng quan điểm với nhận định của T.Y. Jung và cộng sự (2006) đã sử dụng hệ thống định vị trong nghiên cứu của mình và cho rằng hệ thống rất hữu ích để xác định quỹ đạo phù hợp, lựa chọn đường vào u ngắn nhất, đường rạch da và mở nắp sọ nhỏ, đường rạch vỏ não tối ưu, ít tổn thương não nhất với những trường hợp khối u nằm dưới vỏ, những khối u nhỏ nằm ở sâu, xác định chính xác vị trí khối u nằm ở vùng vỏ não vận động, ngôn ngữ, đưa ra quyết định chọn lối vào thích hợp và loại bỏ khối u một cách an toàn [2]. Ứng dụng hệ thống định vị và vi phẫu thuật là phương pháp đáng tin cậy để có được kết quả tốt trong điêu trị các tổn thương là u não ở sâư [6].

4.3. Kết quả phâ̂u thuâat lây u. Ứng dụng neuronavigation trong phẫu thuật, chúng tôi lấy u toàn bộ chiếm 76,4\% (55/72 bệnh nhân). Lây u gân toàn bộ chiếm 18,1\%, để lại một phân u vì những bệnh nhân này u xâm lấn vào các cấu trúc quan trọng như thân não, thể trai, đồi thị...hay bọc bao quanh các động mạch lớn như động mạch cảnh trong, động mạch não giữa, não trước, xoang tĩnh mạch dọc trên, dây thân kinh thị giác, vùng vận động. Lấy bán phân ở 3 bệnh nhân (4,2\%), cũng do u xâm lấn cấu trúc quan trọng và thâm nhiếm nhu mô não rộng. 1 bênh nhân chỉ lấy u được môt phần do u khá chắc nằm sát thành não thất và một phân chui trong não thất, dính chặt với đám rối mạch mạc. Abdullah al-akayleh (2009) sử dụng hệ thống neuronavigation hỗ trợ phẩu thuật cho 40 bệnh nhân u não các loai ở các vị trí khác nhau. Phẫu thuật cắt bỏ toàn bộ khối u ở 35/40 bệnh nhân, giúp bảo vệ cấu trúc quan trọng xung quanh khối u như vùng vỏ não vận động và các cấu trúc thân kinh mạch máu. Còn 5 bênh nhân do khối u bao bọc xung quanh mạch và xâm lấn vào vùng chức năng nên chỉ cắt bỏ một phân. Hệ thống hướng dấn hình ảnh ba chiều tương tác cho phép nhắm đến mục tiêu chính xác, an toàn hơn. Nó là một công cụ hữu ích để nâng cao sự tự tin của bác sĩ phẫu thuật và tối ưu hóa kết quả phẫu thuật [1].

Theo Barnett (1995), 98\% số bệnh nhân cắt bỏ u toàn bộ và tránh được tổn thương xoang tĩnh mạch, động mạch cảnh trong và các động mạch vùng nền sọ [4]. Benveniste và cộng sự (2005) báo cáo 54 bênh nhân trải qua phẫu thuật lấy u dưới sự hướng dẫn của hệ thống định vị (9 u di căn não, 45 u thân kinh đệm bậc cao), có 47 bênh nhân đã được loại bỏ khối u hoàn toàn, 11 bệnh nhân để lại một phân nhỏ u do thâm nhiễm vào vỏ não vùng trội như dải vận động, phân tiếp giáp với thành tâm thất, khe Sylvien, và phần trong thể chai [3]. Nhìn chung, việc sử dụng neuronavigation đã cho thây một Iợi ích rõ ràng, trợ giúp trong việc cắt bỏ các khối u não đăc biệt là các khối u não ác tính, u di căn não, vì chúng thường thâm nhiễm vào mô não lành lân cân, gây khó khăn khi loại bỏ mà không dẫn đến sự thương tổn về thần kinh. 
4.4. Thời gian phẫu thuật. Thời gian phẫu thuật trung bình của chúng tôi là $163,47 \pm 84,64$ phút, tính thời gian từ lúc cài đặt hệ thống cho đến khi đóng xong da đầu. Thời gian của nhóm nghiên cứu không có sự khác biệt nhiều so với tác giả Paleologos (2000) đó là thời gian phẫu thuật trung bình của nhóm có sử dụng hệ thống định vị là 174 phút, so với nhóm phẫu thuật không sử dung hê thống đinh vị là 204 phút [5].

4.5. Kết quả cải thiện chất lượng sống sau mổ. Điểm Karnofsky của bệnh nhân trước mổ và sau mổ là khác biệt có ý nghĩa thống kê với $p<0,05$. Đa số các bệnh nhân đều cải thiên chất lượng cuộc sống sau mổ tốt hơn so với trước mổ chiếm 87,5\% (Karnofsky thuộc nhóm I, II). Chúng tôi nhận thây rằng ứng dụng hệ thống định vị thần kinh trong phẫu thuật u bán cầu đại não đem lại kết quả tốt cho bệnh nhân.

\section{KẾT LUẬN}

Ứng dụng Neuronavigation trong phẫu thuật u bán câu đại não giúp phẫu thuật viên tự tin cắt bỏ tối đa u não, tăng độ an toàn, bảo tồn vùng chức năng cho kết quả cải thiện chất lượng sống bệnh nhân cao.

\section{TÀI LIÊU THAM KHẢO}

1. Abdullah al-akayleh (2009). Application of neuronavigation in Neurosurgery at King Hussein Medical Center, Jordan.

2. T.Y. Jung et al (2006). Application of Neuronavigation System to Brain Tumor Surger y with Clinical Experience of 420 Cases. Minim Invas Neurosurg 2006; 49: 210-215.

3. R. J. Benveniste, I. M. Germano (2005). Correlation of factors predicting intraoperative brain shift with successful resection of malignant brain tumors using image-guided techniques. Surgical Neurology 63 (2005) 542-549.

4. Gene H. Barnett (1995). Intracranial Meningioma Resection Using Frameless Stereotaxy. Journal of Image Guided Surgery 1:105-52 (1995).

5. Paleologos TS et al (2000). Clinical utility and cost-effectiveness of interactive image-guided craniotomy: Clinical comparison between conventional and image-guided meningioma surgery. Neurosurgery 2000 Jul; 47(1):40-7.

6. Ayhan ONK et al (2003). Treatment of deepseated cerebral lesions by stereotactic craniotomy. Gazi Medical Journal 2003; 14; 23-28.

7. Kiêu Đình Hùng (2010). Ứng dụng navigation (hệ thống định vị) trong phẫu thuật u não tại bệnh viện Đại học Y Hà Nội. Tapp chí Nghiên cứu Y học 2010, phu trương 67 (2), tr $8-12$.

8. Chu Tân Sĩ (2012). Nhận xét kết quả phẫu thuât u não tại Bênh viện nhấn dân 115 . Y học TP. Hồ Chí Minh 2012, tập 16 - số 1.

\section{MỐI LIÊN QUAN GIŨ̃A THANG ĐIỂM VẬN ĐộNG VÀ TÌNH TRẠNG CHÂ̂M LÀM TRỐNG DẠ DÀY TRONG BỆNH PARKINSON}

\section{Trần Thanh Hùng*, Vũ Anh Nhị*, Nguyễn Xuân Cảnh**}

\section{TÓM TẮT}

Mở đâu: Bệnh Parkinson là bệnh thoái hóa thần kinh thường gặp đứng hàng thứ hai sau bệnh Alzheimer. Chân đoán chậm làm trống dạ dày có ý nghĩa rất quan trọng trong điều trị bệnh nhân bênh Parkinson. Mục tiêu nghiên cứu: khảo sát mối liên quan giữa thang điểm vận động và tình trạng chậm làm trống dạ dày trong bệnh Parkinson. Phương pháp nghiên cứu: nghiên cứu cắt ngang mô tả, tiến cứu trên bệnh nhân mắc bệnh Parkinson và ký đồng ý tham gia nghiên cứu. Bệnh nhân được đánh giá thang điểm vận động và được thực hiện xạ hình làm trống dạ dày với thức ăn đặc để đánh giá tình trạng chậm làm trống dạ dày. Số liệu được xử lý bằng phần mểm $\mathrm{R}$ phiên bản 4.0.3. Kết quả: Nghiên cứu gồm 72 bênh nhân Parkinson trong đó nữ giới chiếm 73,6\%. Tî̉ lệ

*Đại học Y dược Thành phố Hồ Chí Minh

**Bênh viện Chợ Rẫy

Chịu trách nhiệm chính: Trần Thanh Hùng

Email: tranthanhhungmd@ump.edu.vn

Ngày nhận bài: 2.4.2021

Ngày phản biện khoa học: 21.5.2021

Ngày duyệt bài: 2.6 .2021 chậm làm trống dạ dày trên xạ hình là 45,8\%. Điểm số triệu chứng chậm vận động toàn thân, tăng trương lực cở ngoại tháp, thay đổi tư thế đứng càng cao thì càng có nguy cơ chậm làm trống dạ dày, ngược lại điểm số triệu chứng run tay tứ thế càng cao thì càng ít có nguy cơ chậm làm trống dạ dày, kiểm định Kruskall-Wallis, $p$ tương ứng là: 0,$007 ; 0,041 ; 0,002$; 0,027 . Kết luận: cân nhận biết các kiêuu hình lâm sàng khác nhau của bênh Parkinson, từ đó tiến hành khảo sát tình trang chậm làmm trống dạ dày ở bệnh nhân.

Tì̛ khóa: thang điếm MDS UPDRS phần III, chậm làm trống dạ dày.

\section{SUMMARY \\ CORRELATION BETWEEN MOTOR SCALE AND DELAYED GASTRIC EMPTYING IN PARKINSON DISEASE}

Background: Parkinson's disease (PD) is the second most common neurodegenerative disease after Alzheimer disease. Delayed gastric emptying could be impactful in treatment of PD patients. Objectives: To investigate the correlation between motor scale and delayed gastric emptying in PD. Methods: A crosssectional study was conducted on PD patients with their informed consent. Patients were evaluated on 